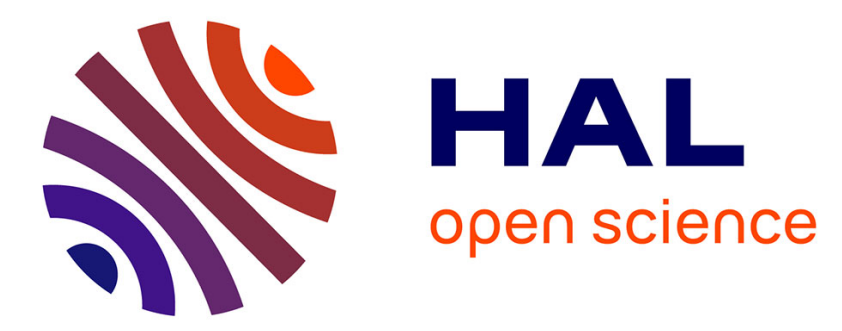

\title{
Strength of a granular medium reinforced by cement grouting
}

\author{
Yamen Maalej, Luc Dormieux, Jean Canou, Jean Claude Dupla
}

\section{To cite this version:}

Yamen Maalej, Luc Dormieux, Jean Canou, Jean Claude Dupla. Strength of a granular medium reinforced by cement grouting. Comptes Rendus Mécanique, 2007, 335 (2), pp.87-92. 10.1016/j.crme.2006.12.003 . hal-00141093

\section{HAL Id: hal-00141093 \\ https://hal.science/hal-00141093}

Submitted on 11 Apr 2007

HAL is a multi-disciplinary open access archive for the deposit and dissemination of scientific research documents, whether they are published or not. The documents may come from teaching and research institutions in France or abroad, or from public or private research centers.
L'archive ouverte pluridisciplinaire HAL, est destinée au dépôt et à la diffusion de documents scientifiques de niveau recherche, publiés ou non, émanant des établissements d'enseignement et de recherche français ou étrangers, des laboratoires publics ou privés. 


\title{
Strength of a granular medium reinforced by cement grouting
}

\author{
Yamen Maalej ${ }^{\mathrm{a}, \mathrm{b}}$ Luc Dormieux ${ }^{\mathrm{a}, *}$ Jean Canou ${ }^{\mathrm{b}}$ Jean Claude Dupla ${ }^{\mathrm{b}}$ \\ ${ }^{\mathrm{a}}$ LMSGC, Institut Navier, École nationale des ponts et chaussées, 6 et 8, avenue Blaise-Pascal, Champs-sur-Marne, \\ 77455 Marne-la-Vallée, France \\ ${ }^{\mathrm{b}}$ CERMES, Institut Navier \\ Received $* * * * *$; accepted after revision +++++ \\ Presented by ččččč
}

\begin{abstract}
The present note describes an experimental study devoted to the strength of a sand reinforced by cement grouting. Through grouting, the granular medium gains a cohesion without significant change of the friction angle. The most significant experimental feature is that the cohesion is proportional to the volume fraction of cement in the grouted material. This result is interpreted within the framework of a periodic homogenization applied to yield design. To cite this article: Y. Maalej et al., C. R. Mecanique 333 (2005).
\end{abstract}

\section{Résumé}

Résistance d'un milieu granulaire renforcé par injection de ciment. On présente une étude expérimentale consacrée aux capacités de résistance d'un sable injecté par un coulis de ciment. L'effet principal de l'injection est un gain de cohésion sans modification significative de l'angle de frottement. La principale observation expérimentale réside dans le fait que la cohésion est proportionnelle à la fraction volumique de ciment réalisée dans le matériau injecté. On interprète ce résultat dans le cadre de l'homogénéisation périodique en Calcul à la Rupture. Pour citer cet article : Y. Maalej et al., C. R. Mecanique 333 (2005).

Key words: Granular medium; Cement grouting ; Strength criterion ; Limit analysis ; Homogenization

Mots-clés : Milieu granulaire; Injection de ciment; Critère de rupture; Calcul à la Rupture ; Homogénéisation

\section{Introduction}

Cement grouting in granular media is a widely used technique in civil engineering, applied in order to improve the mechanical characteristics of soils ([1]). The idea consists in incorporating a pressurized

Email addresses: maalej@lmsgc.enpc.fr (Yamen Maalej), dormieux@lmsgc.enpc.fr (Luc Dormieux). 
cement grout in the pore space of the soil. The setting of cement in the pore space increases both the stiffness and the strength ([2], [3]). The resulting microstructure is a heterogeneous material made up of sand grains, cement and pores.

Several experimental studies on reference sand have been devoted to the increase of the strength due to cement grouting ([3], [4]). These works show that the grouted material remains a frictional one, the strength of which is correctly modelled by Mohr-Coulomb criterion. Grouting is mainly responsible for the cohesion gained by the material and only slightly affects the friction angle.

The present note describes the results of an experimental study devoted to the strength of a grouted Fontainebleau sand, with special focus on the influence of the cement volume fraction. It confirms the qualitative trends already reported on the nature of the failure criterion of grouted materials. The main contribution of the present work is the experimental and theoretical analysis of the influence of the cement volume fraction on the cohesion gained through grouting.

\section{Experimental set up}

The samples of grouted sand are obtained from the grouting set up described in ([5], [6]). A plexiglas column (height $108 \mathrm{~cm}$, diameter $8 \mathrm{~cm}$ ) is first filled with Fontainebleau sand by a pluviation technique at a density index $I_{d}=0.9$, corresponding to an initial porosity $\phi_{0}=0.37$. After water saturation of the column, a fine cement grout (Spinor A12) is then injected from the bottom to the top. The cement/water mass ratio, denoted by $C / E$, is controlled during injection. In the present study, the values $C / E=0.1$ and 0.2 have been considered.

After injection of the grout, the column is kept under wet conditions during 28 days. It is finally cut into five $160 \times 80 \mathrm{~mm}$ samples, numbered from 1 to 5 from the bottom to the top (see Fig. 1(a)).

The samples are then water saturated and subjected to a confining pressure in a triaxial apparatus. Drained triaxial compression tests under constant confining pressure are then performed. The limit load is measured as a function of the confining pressure. In addition, triaxial tests have been performed on pure Fontainebleau sand samples prepared at the same density index $I_{d}=0.9$.

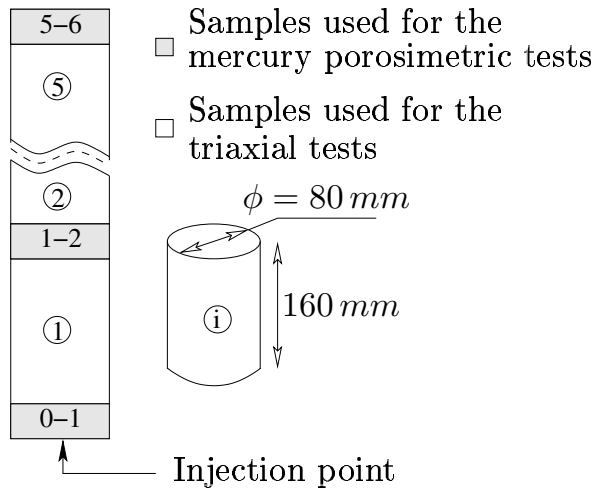

(a)

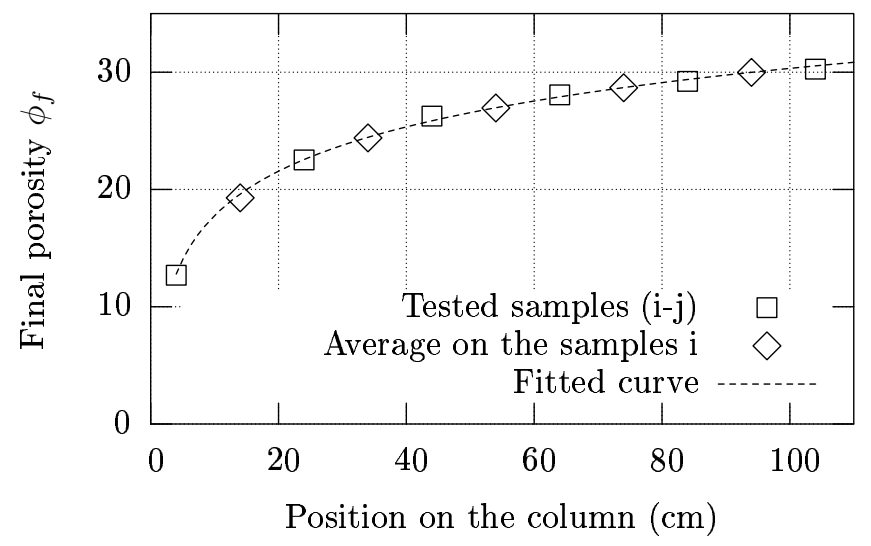

(b)

Figure 1. (a) Injected sand column with numbered samples; (b) Final porosity $\phi_{f}$ as function of the location of sample along the column 


\section{Experimental results}

The purpose of the experimental study is to evaluate the influence of the cement volume fraction $\phi_{c}$ on the strength. The final porosity $\phi_{f}$ is determined by mercury porosimetry for each level in the column [2]. Clearly enough, the cement volume fraction $\phi_{c}$ is equal to the decrease $\phi_{0}-\phi_{f}$ of the porosity. $\phi_{c}$ decreases as the distance to the injection source increases (Fig. 1(b)).

Identical triaxial tests have been performed for each level in the column. Figure 2(a) presents the results of five triaxial compression tests corresponding to five different confining pressure $p_{c}$ ranging from 100 $\mathrm{kPa}$ to $1000 \mathrm{kPa}$. These tests have been performed on samples of level 2 taken from 5 different columns prepared identically. Figure 2(b) plots the stress pathes in the classical $(p, q)$ plane, where $p=-\frac{1}{3} \operatorname{tr} \sigma$ is the mean effective stress and $q$ is the difference between the axial compression stress and the confining pressure. The boundary of the admissible stress states in this plane is found to be a straight line.

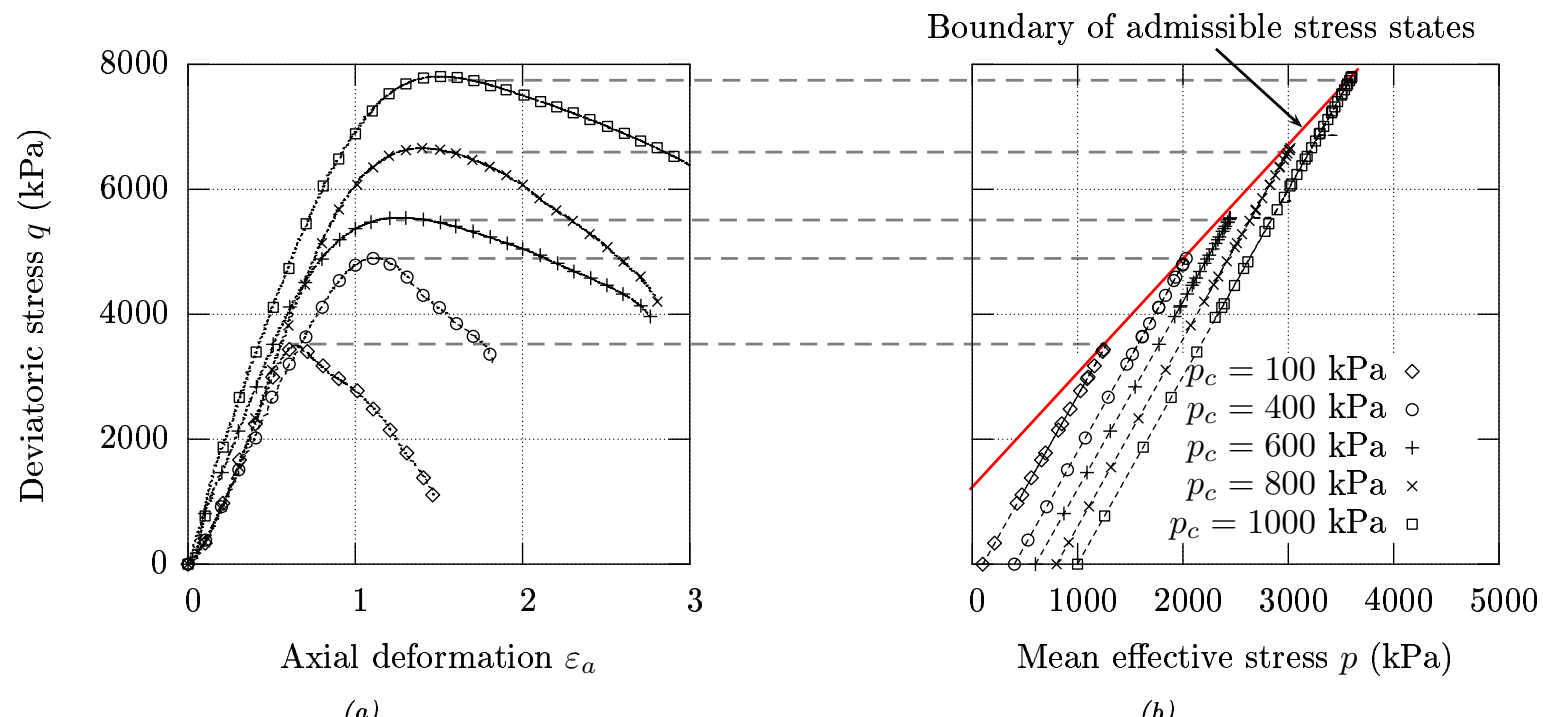

(a)

(b)

Figure 2. Triaxial tests results (a) and failure criterion (b), ( $p_{c}$ is the initial confining pressure applied in each tests)

Disregarding possible role of the intermediate principal stress (which cannot be investigated with the classical triaxial apparatus), this result confirms that the strength of a grouted sand is correctly described by a Mohr-Coulomb criterion (friction angle $\varphi^{i n j}$, cohesion $C^{i n j}$ ). These two parameters are classically related to the slope $M_{p q}$ and to the ordinate at the origin $C_{p q}$ by :

$$
\varphi^{i n j}=\arcsin \left(\frac{3 M_{p q}}{6+M_{p q}}\right) \quad \text { et } \quad C^{i n j}=\frac{3-\sin \varphi^{i n j}}{6 \cos \varphi^{i n j}} C_{p q}
$$

The data plotted in figure 3 concerning the influence of $\phi_{c}$ on $C^{i n j}$ and $\varphi^{i n j}$ represent the original experimental contribution of the present note. Each point corresponds to a specific cement volume fraction, associated with $C / E=0.1$ or 0.2 and with a particular level in the column (levels 1,3 and 5 for $C / E=0.1$, and levels 1 to 5 for $C / E=0.2$ ).

The most significant conclusions that can be drawn from figure 3 are (1) the linearity of the variations of $C^{i n j}$ with respect to $\phi_{c}$ (see Fig. 3(a)) and (2) the order of magnitude of the cohesion gained by grouting (several hundred of $\mathrm{kPa}$ ). Figure 3(b) also reveals that the friction angle $\varphi^{i n j}$ is a slightly increasing 


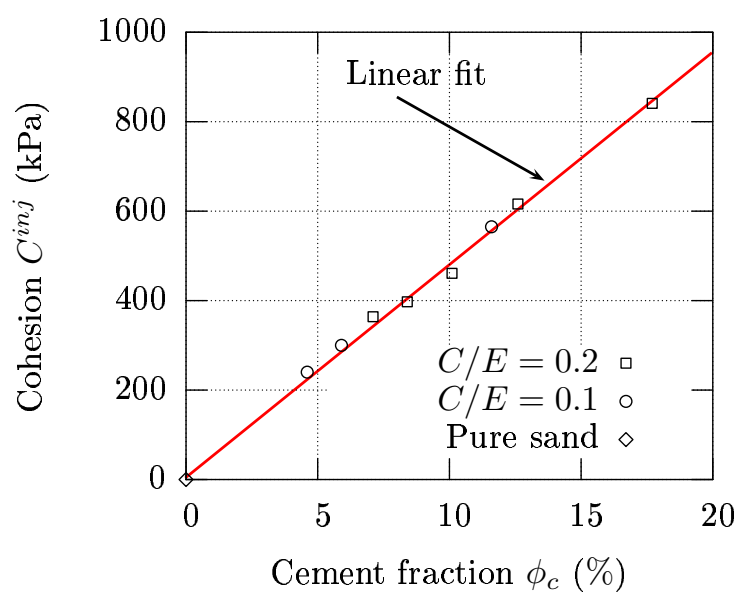

(a)

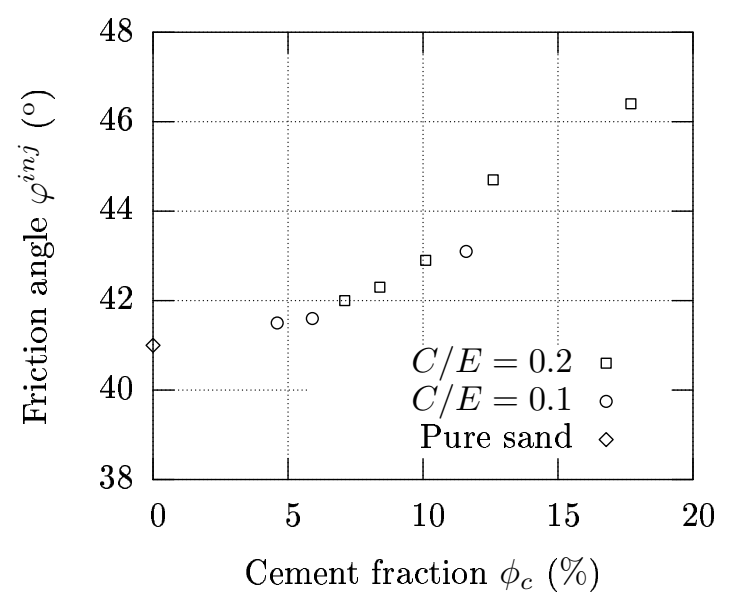

(b)

Figure 3. The variation of the cohesion $C^{i n j}$ (a) and the friction angle $\varphi^{i n j}$ (b) as function of the cement fraction $\phi_{c}$

function of $\phi_{c}$, the maximum discrepancy with respect to the friction angle $\varphi^{s}$ of pure sand being of the order of 5 degrees. The influence of this phenomenon on the strength of the grouted sand is however much weaker than the increase of the cohesion. Indeed, for typical values of the mean stress $p$, say $100 \mathrm{kPa}$, the deviatoric stress $q=p M_{p q}$ varies from $q=168 \mathrm{kPa}$ for $\varphi^{s}=41^{\circ}$ to $q=189 \mathrm{kPa}$ for $\varphi^{i n j}=46^{\circ}$, that is, increases by $21 \mathrm{kPa}$. This increase is negligible with respect to that induced by the cohesion, which can be as high as $900 \mathrm{kPa}$.

\section{Micromechanics interpretation}

The aim of this section is to provide a micromechanics basis to the proportionality observed between the cohesion $C^{i n j}$ and the cement volume fraction $\phi_{c}$. To this end, a periodic model of the microstructure is considered. The latter is characterized by the elementary cell $\mathcal{C}$. From a geometrical point of view, the pure sand is described as a set of spheres with identical radius $a$, in pointwise contact with one another. This kind of simplification is reasonable for a Fontainebleau sand. Moreover, it is assumed that the hydrated cement appears as a layer of thickness $e \ll a$ covering the whole boundary of the grain (figure 4). Neglecting the second order in $e / a$, it is readily seen that this geometrical model implies

$$
\phi_{c}=3 \frac{e}{a}\left(1-\phi_{0}\right)
$$

Following the remark at the end of the previous section, the variation of the friction angle induced by cement grouting is neglected, so that $\varphi^{i n j}$ is taken equal to the friction angle $\varphi^{s}$ of the pure sand.

Considering a macroscopic strain rate $\boldsymbol{D}$, the support function $\Pi(\boldsymbol{D})$ of the homogenized criterion is derived by means of two different approaches. First, taking advantage of the experimental observations concluding that the strength of the grouted sand can be described by a Mohr-Coulomb criterion, the macroscopic derivation of $\Pi(\boldsymbol{D})([7])$ reads

$$
\Pi(\boldsymbol{D})=\frac{C^{i n j}}{\tan \varphi^{i n j}} \operatorname{tr} \boldsymbol{D}
$$




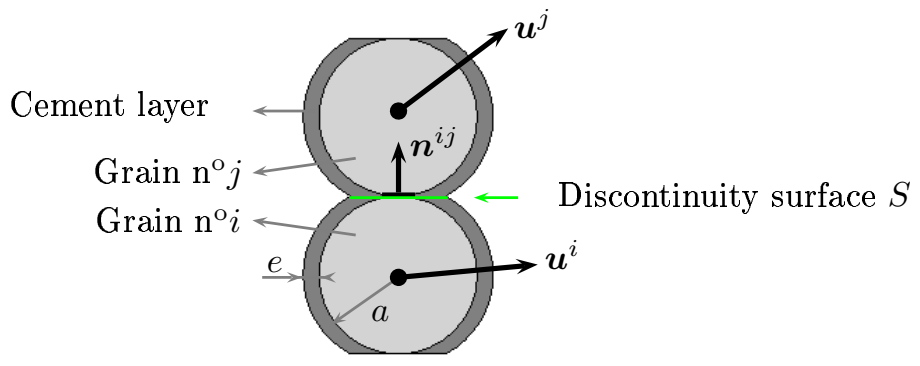

Figure 4. Geometrical model and failure mechanism

provided that $\operatorname{tr} \boldsymbol{D} \geq\left(\sum_{i}\left|D_{i}\right|\right) \sin \varphi^{i n j}$, where $D_{i}$ denote the eigenvalues of the strain rate $\boldsymbol{D}$.

Let us now examine the micromechanics interpretation to $\Pi(\boldsymbol{D})$. The first step consists in modelling the strength of the components of the microstructure. It is assumed that the strength of the grains is infinite and that the intergranular forces obey a cohesionless Mohr-Coulomb criterion, with friction angle $\varphi^{g}$. More precisely, let $C^{i j}$ denote the contact point between grains $\mathrm{n}^{\circ} i$ and $\mathrm{n}^{\circ} j$, and $\boldsymbol{n}^{i j}$ be the unit normal to the contact plane, oriented from grain $\mathrm{n}^{\circ} i$ toward grain $\mathrm{n}^{\circ} j$. The normal and tangential components to the force $\boldsymbol{F}^{i j}$ applied on grain $\mathrm{n}^{\circ} i$ by grain $\mathrm{n}^{\mathrm{o}} j$ read

$$
F_{n}^{i j}=\boldsymbol{F}^{i j} \cdot \boldsymbol{n}^{i j} \quad ; \quad F_{t}^{i j}=\left|\boldsymbol{F}^{i j}-F_{n}^{i j} \boldsymbol{n}^{i j}\right|
$$

and are subjected to the condition $F_{t}^{i j}+\tan \varphi^{g} F_{n}^{i j} \leq 0$. A Tresca criterion (cohesion $C^{c}$ ) without tensile strength is adopted for the hydrated cement phase.

Let $\mathcal{K}$ denote the set of velocity fields defined on $\mathcal{C}$ at the microscopic scale, (i) which are kinematically admissible with $\boldsymbol{D}$ and (ii) for which the maximum resisting work is finite for the given strength properties of the microstructure. Since the strength of the grains is infinite, this condition (ii) implies that the restriction of such a velocity field $\boldsymbol{u}$ to a given grain is a rigid body motion. It can be shown ([8]) that it is possible, without loss of generality, to neglect the rotation component of the grains velocity, so that they are subjected to translations. Let $\boldsymbol{u}^{i j}$ denote the discontinuity $\boldsymbol{u}^{j}-\boldsymbol{u}^{i}$ at the contact point $C^{i j}$. The normal and tangential components of $\boldsymbol{u}^{i j}$ read

$$
u_{n}^{i j}=\boldsymbol{u}^{i j} \cdot \boldsymbol{n}^{i j} \quad ; \quad u_{t}^{i j}=\left|\boldsymbol{u}^{i j}-u_{n}^{i j} \boldsymbol{n}^{i j}\right|
$$

The velocity field $\boldsymbol{u}$ must be extended to the cement layers surrounding the grains in a way which must be compatible with the velocity discontinuities at the contact points. The simplest model consists in assuming that the cement phase surrounding grain $i$ (resp. $j$ ) is subjected to the same translation as this grain, so that we have to introduce a velocity discontinuity equal to $\boldsymbol{u}^{i j}$, located in the plane tangent to these grains at the point $C^{i j}$ (figure 4). This model is relevant with respect to condition (ii) provided that $u_{n}^{i j} \geq 0$, which means that the contribution of this discontinuity to the resisting work is finite. The area $S$ of the discontinuity surface in the tangent plane is $\pi\left((a+e)^{2}-a^{2}\right)$, that is, neglecting the second order in $e / a$ and using (2) :

$$
S=\frac{2 \pi a^{2}}{3\left(1-\phi_{0}\right)} \phi_{c}
$$

The condition (ii) to be satisfied by the velocity fields of $\mathcal{K}$ reduces to :

$$
(\forall\{i, j\}) \quad \frac{u_{n}^{i j}}{u_{t}^{i j}} \geq \tan \varphi^{g}
$$

Since these conditions are not affected by the presence of cement in the microstructure, the set $\mathcal{K}$ is itself independent of the cement volume fraction $\phi_{c}$. According to the micromechanics definition of $\Pi(\boldsymbol{D})([9])$, $\Pi(\boldsymbol{D})$ appears to be the sum of the contributions of each discontinuity zone in the cement phase : 


$$
\Pi(\boldsymbol{D})=C^{c} \frac{S}{|\mathcal{C}|} \mathcal{U} \quad \text { with } \quad \mathcal{U}=\inf _{\boldsymbol{u} \in \mathcal{K}}\left(\sum_{\{i, j\}} u_{t}^{i j}\right)
$$

where $|\mathcal{C}|$ denotes the volume of the elementary cell. The quantity $\mathcal{U}$ involved in (8) only depends on the geometry of the pure sand microstructure, and is therefore independent of $\phi_{c}$. Comparing (3) and (8) reveals the existence of a coefficient $\lambda(\mathcal{C})$, purely geometrical in nature, having the dimension of a length, such that $\mathcal{U}=\lambda(\mathcal{C}) \operatorname{tr} \boldsymbol{D}$. This coefficient depends on the morphology of the elementary cell $\mathcal{C}$. Owing to (6), we eventually obtain

$$
C^{i n j}=c \phi_{c} \quad \text { with } \quad c=C^{c} \tan \varphi^{i n j} \frac{2 \pi a^{2} \lambda(\mathcal{C})}{3\left(1-\phi_{0}\right)|\mathcal{C}|}
$$

Within the framework of the approximation in which the variation of $\varphi^{i n j}$ is neglected, the above result establishes the proportionality between the cohesion of the grouted sand and the volume fraction of the cement paste introduced in the pore space. Once the morphology of the granular network is specified, that is, for a specific choice of the elementary cell, $\lambda(\mathcal{C})$ can be determined and (9) can be used for predicting the cohesion gained through grouting.

\section{References}

[1] Cambefort H. (1967) 'Injection des sols, Tome 1 : principes et méthodes', Editions Eyrolles.

[2] Maalej Y., Dormieux L., Canou J., Dupla J.C. (2006) 'Evaluation of the elastic properties of a grouted granular medium using a micromechanics-based model', Advances in Geomaterials and Structures, Tunisia 3-5 May, pp. 687-692.

[3] Dano C. (2001) 'Comportement mécanique des sols injectés', PhD. thesis, Ecole centrale de Nantes, France.

[4] Biarez J., David H., Gouvenot D., Hicher P.-Y., Taillez S. and Varjabedian M. (1998) 'Comportement mécanique des sols granulaires traités par injection' Revue Française de Génie Civil, Vol. 2, No. 2, pp. 225-295.

[5] Saada Z., Canou J., Dormieux L., Dupla J.-C. and Maghous S. (2005) 'Modelling of cement suspension flow in granular porous media', Int. J. Numer. Anal. Meth. Geomech., vol. 29, pp. 691-711.

[6] Dupla J.-C., Canou J. and Gouvenot D. (2004) 'An advanced experimental set-up for studying monodirectional grout injection process', Ground Improvement, Vol. 8, No. 3, pp. 91-99.

[7] Salençon J. (1983) 'Calcul à la Rupture et Analyse Limite', Presses de l'ENPC.

[8] Buhan de P. and de Felice G. (1997) 'A homogenization approach to the ultimate strength of brick masonry', J. Mech. Phys. Solids, Vol. 45, No. 7, pp 1085-1104.

[9] Buhan de P. (1986) 'Approche fondamentale du Calcul à la Rupture des ouvrages en sols renforcés', Thèse d'Etat, Univ. Paris VI, France. 